\title{
Development of Electrochemical Aptamer Biosensor for Tumor Marker MUC1 Determination
}

\author{
Jinhua Song ${ }^{\# 1}$, Yun Zhou ${ }^{2 \#}$, Bech Chen ${ }^{3}$, Wensheng Lou ${ }^{l}$ and Jianping Gu ${ }^{1, *}$ \\ ${ }^{1}$ Department of Interventional Radiology, Nanjing First Hospital, Nanjing Medical University, 68 \\ Changle Road,Nanjing City, Jiangsu Province, 210006, P.R. China \\ ${ }^{2}$ Department of Ultrasound, Nanjing First Hospital, Nanjing Medical University, 76 Changle \\ Rd,Nanjing City, Jiangsu Province, 210006, P.R. China \\ ${ }^{3}$ Department of Diagnostic Radiology of City of Hope, 1500 East Duarte Road, Duarte, CA, 91010, \\ USA \\ \# These authors contributed equally to this work \\ *E-mail: cjr.gujianping@vip.163.com
}

doi: $10.20964 / 2017.06 .46$

Received: 9 March 2017 / Accepted: 21 April 2017 / Published: 12 May 2017

\begin{abstract}
With global-scale conformational \& analyte-binding caused variation with respect to electrode-bound anti-MUC1 DNA aptamers as the basis, mucin 1 (MUC1) as a glycoprotein expressed on a majority of epithelial cell surfaces was quantitatively determined via an aptamer-based electrochemical biosensor proposed in this work. On the basis of the specific recognition of the MUC1 tumor marker through the thiolated aptamers that went through immobilization onto the glassy carbon electrode (GCE) modified by $\mathrm{Au}$ nanoparticle (Au NP), we designed electrochemical aptasensors to detect the MUC1 tumor marker. The differential pulse voltammetry (DPV), together with the electrochemical impedance spectroscopy (EIS) was utilized for quantitatively detecting MUC1 protein. This system excels the enzyme-linked immunosorbent assay (ELISA) kits on the market in its dynamic response range as high as $1.0 \mu \mathrm{M} \&$ detection limit as low as $30 \mathrm{nM}$.
\end{abstract}

Keywords: Mucin 1; Aptasensor; Gold nanoparticle; Cyclic voltammetry; Differential pulse voltammetry

\section{FULL TEXT}

(C) 2017 The Authors. Published by ESG (www.electrochemsci.org). This article is an open access article distributed under the terms and conditions of the Creative Commons Attribution license (http://creativecommons.org/licenses/by/4.0/). 